ARTIGO DE REVISÃO

\title{
ESTAFILOCOCOS EM ALIMENTOS
}

\section{E.H.W. de Santana ${ }^{1}$, V. Beloti ${ }^{2}$, L.C. Aragon-alegro ${ }^{1}$, M.B.O.C. de Mendonça ${ }^{1}$}

${ }^{1}$ Universidade Norte do Paraná, Centro de Pesquisa em Ciência e Tecnologia do Leite, Av. Paris, 675, CEP 86041-100, Londrina, PR, Brasil. E-mail:elsahws@hotmail.com

\section{RESUMO}

\begin{abstract}
Este artigo de revisão tem como objetivo descrever as principais características do Staphylocococus aureus e a relação deste micro-organismo com as doenças transmitidas por alimentos. S. aureus é a principal espécie do gênero e o homem e os animais são os reservatórios. Este micro-organismo se multiplica com facilidade em vários alimentos e produz enterotoxinas (EE) termorresistentes. Leite cru e derivados, creme, tortas recheadas com creme, salada de batata, atum, carne de frango, presunto, carnes e produtos a base de ovos já foram incriminados nos surtos alimentares envolvendo os estafilococos. Os principais sintomas são náuseas, vômito, cãibras abdominais e diarréia. O período de incubação varia de 2 a 4 horas. São conhecidos 20 tipos diferentes de EE e sua produção é influenciada pela temperatura, $\mathrm{pH}$, atividade de água, tamanho do inóculo, fonte de carbono e nitrogênio, concentração de sal e condições atmosféricas do substrato. A maioria das intoxicações é produzida por EEA e EED. As EE são detectáveis nos alimentos que apresentam populações de $S$. aureus acima de $10^{5} \mathrm{UFC} / \mathrm{mL}$ de alimento. A dose mínima de EE ingerida para causar intoxicação é 100 ng. Para detecção de EE, existem métodos como Sensibilidade Ótima em Placas (OSP- Optimun Sensitivity Place), microslide, Aglutinação Reversa Passiva em Látex (RPLA- Reversed Passive Latex Agglutination) e ELISA. A Reação em Cadeia pela Polimerase (PCR- Polimerase Chain Reaction), apesar de não diferenciar células viáveis de não viáveis, pode ser aplicada para detecção de diversos tipos de estafilococos enterotoxigênicos.
\end{abstract}

PALAVRAS-CHAVE: Entetotoxina, intoxicação estafilocócica, DTA.

\section{ABSTRACT}

STAPHILOCOCCI IN FOOD. This review article aims to describe the main characteristics of Staphylocococus aureus and the relation of this microorganism with food-borne disease. S. aureus is the main species of this genus, and man and animals are the main reservoirs. These microorganisms can easily grow in food and produce thermo-resistant enterotoxins. Whole milk and dairy products, cream, cream-filled pies, potato salad, tuna, chicken, ham, meat and egg-based products have been incriminated in food-borne outbreaks involving Staphylococcus. The main symptoms are nausea, vomit, abdominal cramps and diarrhea. The incubation period varies from 2 to 4 hours. Twenty different enterotoxins are known and their production is influenced by temperature, $\mathrm{pH}$, water activity, inoculum size, carbon and nitrogen availability, salt concentration and atmospheric conditions. The majority of food poisoning is caused by enterotoxins $\mathrm{A}$ and $\mathrm{E}$. The enterotoxins are detectable in food containing S. aureus populations above $105 \mathrm{CFU} / \mathrm{mL}$. The minimum dose of enterotoxin necessary to cause staphylococcal poisoning is $100 \mathrm{ng}$. To detect enterotoxins, methods like optimum sensitivity plate (OSP), microslide, reversed passive latex agglutination (RPLA) and ELISA can be applied. Although polimerase chain reaction (PCR) cannot differentiate viable and nonviable cells, it can be used to detect different kinds of enterotoxigenic staphylococci.

KEY WORDS: Enterotoxin, staphylococcal poisoning, food-borne disease.

\section{INTRODUÇÃO}

As Doenças Transmitidas por Alimentos (DTAs) são consideradas, atualmente, um grande problema para a saúde pública mundial. Oficialmente, surtos são definidos como sendo a ocorrência de dois ou mais casos de uma doença, com o mesmo quadro clínico, resultante da ingestão de um alimento em

${ }^{2}$ Universidade Estadual de Londrina, Centro de Ciências Agrárias, Departamento de Medicina Veterinária Preventiva, Londrina, PR, Brasil. 
comum (Meer; Misner,1999). Acredita-se que nos países desenvolvidos, em média, $70 \%$ dos casos de diarreia que acometem crianças com menos de cinco anos têm origem alimentar (World Health Orgazization, 1995). Segundo o Centro para o Controle e Prevenção de Doenças "CDC - Center for Diseases Control" (CEnTER FOR Diseases CONTROL, 2009), ocorrem anualmente 38,6 milhões de casos de doenças gastrointestinais causadas por patógenos conhecidos e 13,6 milhões (36\%) deste total são atribuídos as DTAs.

Suspeita-se que, a cada ano, 76 milhões de americanos são acometidos por doenças veiculadas por alimentos, ocorrendo 325 mil hospitalizações e 5.200 mortes. Deste total os micro-organismos foram responsáveis por cerca de 14 milhões toxinfecções, 60 mil hospitalizações e 1.800 mortes (CENTER FOR Diseases Control 2009). Crianças, idosos, gestantes e imunocomprometidos são consideradas a população de maior risco (BREWER, 1991). Na França, entre os anos de 1988 e 1997, foram notificados 3.839 surtos de toxinfecção alimentar envolvendo 83.500 pessoas, causando 7.492 hospitalizações e 62 mortes (BUYSER et al., 2001). De acordo com LoIr et al. (2003), na França, em dois anos (1999-2000), ocorreram 1.267 surtos de doenças veiculadas por alimentos, envolvendo 17.378 pessoas com 1.383 hospitalizações e uma morte. Em uma revisão sobre surtos de toxinfecção alimentar em escolas dos Estados Unidos, DANIELS et al. (2002) relataram que, entre os anos de 1973 e 1997, foi comunicado ao CDC um total de 604 surtos de toxinfecção com 49.963 doentes, 1.514 hospitalizações e uma morte. Sabe-se também que, além dos problemas associados à saúde pública, as DTAs geram um custo alto aos países como os EUA, que gastam entre 5 e 17 bilhões de dólares com medicamentos, internamentos e queda na produtividade (BREWER, 1991)

Os contaminantes microbiológicos, principalmente os bacterianos, são os principais agentes associados aos quadros de toxinfecções alimentares (Loir et al., 2003; World Health Orgazization, 1995). Em 2000, de acordo com o Departamento de Agricultura dos Estados Unidos (U.S. Departament of Agriculture), os patógenos bacterianos causadores de doenças alimentares geraram um gasto de 6,9 bilhões de dólares (U.S. Departament of Agriculture, 2004). Entre os micro-organismos associados aos quadros de toxinfecções alimentares, o Staphylococcus aureus representa 4,5\% das DTAs que ocorrem anualmente nos EUA, o que corresponde, em média, a 185.000 doentes, 1.753 hospitalizações e 2 mortes (U.S. Departament of Agriculture, 2001). De acordo com o CDC, entre 1993 e 1997 foram notificados, nos EUA, 42 surtos de intoxicação estafilocócica, envolvendo 1.413 pessoas e causando um óbito (CENTER FOR DisEASES CONTROL, 2000). Segundo DANiels et al. (2002), do total de toxinfecções que ocorreram em escolas nos EUA entre 1973 e 1997, o agente etiológico foi descrito em $40 \%$ dos casos e, deste total, $85 \%$ foram causados por bactérias, sendo o $S$. aureus responsável por $25 \%$ deles, resultando em 6.521 pessoas doentes e 319 hospitalizações. Este micro-organismo é considerado um agente de grande importância, pois tem alta frequência como contaminante e grande potencial como causador de intoxicações (ZECCONI; HAHN, 2001; DingEs et al., 2000). Essas intoxicações são causadas pela ingestão de enterotoxinas préformadas no alimento durante a multiplicação bacteriana, destacando-se aqueles alimentos de origem animal (BREWER, 1991).

Em 2000, no Japão, 13.420 pessoas foram envolvidas em um surto de intoxicação ao consumirem leite desnatado reconstituído contaminado com enterotoxina A e $\mathrm{H}$ produzidas por estafilococos (IKEDA et al., 2005). Na França, entre 1999 e 2000, o S. aureus foi apontado como o segundo maior responsável pelos casos de DTA microbiana naquele país (LoIR et al., 2003).

No Brasil, são poucas as informações quanto às doenças transmitidas por alimentos. Segundo Pereira et al. (1994), as intoxicações estafilocócicas são muito comuns no país, sendo a maioria dos casos não investigada ou não notificada. De acordo com o Instituto Panamericano de Proteção dos AlimenTOS E ZoONOSEs (2002), entre os anos de 1993 e 2002, ocorreram 18 surtos notificados de intoxicação estafilocócica envolvendo produtos lácteos, sendo dois deles o leite. Deste total, 93 pessoas ficaram doentes e não foi notificado nenhum óbito. No Estado deSão Paulo, entre 2001 e 2002, foram notificados 25 surtos de intoxicação por $S$. aureus envolvendo 200 pessoas (Center for Diseases Control, 2003). No Estado de Minas Gerais, segundo relatos da Fundação Ezequiel Dias - FUNED, entre os anos de 1995 e 2001, 12.820 pessoas foram intoxicadase 17 morreram apósingerir alimentos contaminados por EE. Nestes surtos, os alimentos incriminados, em ordem de freqüência, foram refeições prontas, queijos, leite e derivados, bolo recheado, frangos e embutidos, massas e maionese (CARMO, 2002).

Segundo a Secretaria de Saúde do Paraná, em 1998 ocorreram 200 surtos de doenças veiculadas por alimentos envolvendo 1.827 indivíduos, sendo 14 surtos e 94 pessoas envolvidas no Município de Londrina. Do total de surtos daquele ano, apenas 107 tiveram o agente etiológico isolado e identificado, sendo 30 casos associados ao S. aureus e, destes, $31,2 \%$ foram confirmados laboratorialmente e $20 \%$ por meio de suspeita clínica e epidemiológica. Dos alimentos incriminados, nos surtos onde o agente etiológico foi identificado, 15 deles foram associados a alimentos de preparação mista, isto é, que contêm matéria-prima de origem animal e vegetal, 6 surtos 
atribuídos a carne e derivados e 8 a leite e derivados, ovo e suco de maracujá industrializado.

\section{ESTAFILOCOCOS}

Os estafilococos foram observados inicialmente por Kock em 1878 a partir de material purulento e, em 1881, houve a primeira publicação citando a forma de cocos e a presença constante desses microorganismos em abcessos agudos e crônicos. A relação desses micro-organismos com surtos de intoxicação alimentar só ocorreu em 1884, em Michigan, EUA, quando se associou os casos ao consumo de queijo tipo cheddar contaminado com estafilococos (PEREIRA et al., 2000).

Em alimentos, as espécies de maior importância são S. aureus, S. hyicus, S. chromogenes e S. intermedius, (FrANCO; LANDGRAF, 2005; Su; WONG, 1997) sendo $S$. aureus a principal espécie associada aos casos de intoxicação alimentar, representando, em média, 98\% dos surtos por este gênero.

Os estafilococos são micro-organismos mesófilos com temperatura de crescimento entre 7 e $47,8^{\circ} \mathrm{C} \mathrm{e}$ podem produzir enterotoxinas termorresistentes a temperaturas entre $10 \mathrm{e} 46^{\circ} \mathrm{C}$, com temperatura ótima entre $40 \mathrm{e} 45^{\circ} \mathrm{C} . \mathrm{OpHideal}$ para seu desenvolvimento varia entre 7 a 7,5, mas é possível a multiplicação em alimentos com $\mathrm{pH}$ variando entre 4,2 e 9,3. Este grupo de micro-organismos ainda tem a capacidade de sobreviver e se multiplicar em uma concentração de cloreto de sódio de até $15 \%$ e a produção de enterotoxina acontece em concentrações de sal de até $10 \%$, o que faz com que os alimentos curados também sejam veículos potenciais de intoxicação. Quanto à atividade de água (aw) os estafilococos são únicos em sua capacidade de se multiplicarem em alimentos com valores de atividade de água inferiores ao normalmente considerados mínimos para outras bactérias halófilas. O valor mínimo de aw é 0,86 , apesar de já ter sido relatada a multiplicação desses micro-organismos em alimentos com aw de 0,83 (Wong; BERGDOLL, 2002; FRANCO; LANDGRAF, 2005). A presença de outros micro-organismos também é um ponto importante, pois os estafilococos são considerados mal competidores (LoIR et al., 2003). Segundo BAIRD-PARKER (1990), a temperatura para destruição do $S$. aureus varia entre 43 segundos e 8 min a $60^{\circ} \mathrm{C}$, onde as culturas mais jovens apresentam maior sensibilidade a esta mudança de temperatura (WALKer; HARMON, 1966).

A versatilidade nutricional e a capacidade de crescerem em diferentes condições ambientais fazem com que o $S$. aureus desenvolva-se com facilidade em vários alimentos (LOIR et al., 2003; CARMO, 2002).

Existem alguns fatores de virulência dos estafilococos, associados à sua capacidade enterotoxigênica, importantes para o fechamento das conclusões de um processo de investigação epidemiológica. Entreestes fatores de virulência utiliza-se a pesquisa da coagulase e da termonuclease (Tnase) como os indicadores mais aceitos quanto à presuntiva evidência da sua propriedade enterotoxigênica (PEREIRA et al., 2000).

A produção da coagulase, uma enzima extracelular, é uma das provas mais amplamente utilizadas para correlacionar a cepa isolada com a produção de enterotoxina (EE), embora a relação entre a produção da coagulase e a deEE não seja absoluta (WONG; BERGDOLL, 2002; ORDEN et al., 1992). A coagulase promove a transformação do fibrinogênio em fibrina e consequente coagulação do plasma sanguíneo (WONG; Bergdoll, 2002; Pereira et al., 2000). Segundo Silva et al. (2000), grande parte dos laboratórios utiliza-se da prova da coagulase e/ou termonuclease para identificar as cepas de $S$. aureus.

A produção de enterotoxinas por outras espécies de estafilococos coagulase positivos (ECP), como S. intermedius e $S$. hyicus, e outras espécies de estafilococos coagulase negativos $(\mathrm{ECN})$ já foi relatada. Porém, os surtos de intoxicação alimentar estão relacionados à contaminação de alimentos por S. aureus enterotoxigênicos (ZoLi et al., 2002). De acordo com SANTOS (2003), a importância dos ECN em diversas patologias de seres humanos e animais é indiscutível, mas sua participação em surtos de intoxicação alimentar não tem sido verificada. PEREIRA et al. (2001), ao avaliarem o comportamento de ECN pauciprodutores, inocularam estas linhagens emleite UHT e presunto cozido e encontraram contagens de estafilococos variando entre $10^{5}$ e $10^{9} \mathrm{UFC} / \mathrm{mL}$, não sendo possível a detecção da EE nos alimentos em questão. Embora ECN possam produzir quantidades menores de EE quando comparada com S. aureus, esses micro-organismos não devem ser excluídos da investigação quando a ocorrência em surtos de intoxicações alimentares (ORDEN et al., 1992).

\section{EPIDEMIOLOGIA}

O homem e os animais são os principais reservatórios de $S$. aureus, sendo a cavidade nasal do homem seu principal habitat (FRANCO; LANDGRAF, 2005; WONG; BERGDOLL, 2002) e pode ser encontrado em $30 \%$ a $50 \%$ dos indivíduos saudáveis (Lorr et al., 2003; Wong; BERGDOLL, 2002; U.S. FoOD AND DRUG ADMISTRATION, 1992; BREWER, 1991). Éa partir da cavidade nasal que o micro-organismo atinge a epiderme, ar, água, solo, alimentos, ou qualquer outro objeto que entre em contato com o indivíduo. Os portadores nasais de S. aureus ao manipularem alimentos podem se tornar importante fonte de contaminação para os alimentos (FrANCO; LANDGRAF, 2005; AsPerger, 1994; LANCETte; TATINI, 1992).

S. aureus é um dos principais agentes causadores de infecções na glândula mamária de vacas produto- 
ras de leite (CENCI-GOGA, 2003; WonG; BERGDOLL, 2002; ZECCONI; HAHN , 2001; AKINEDEN et al., 2001, SILVA et al. 2000; LANCETTE; TATINI , 1992), sendo considerado o micro-organismo patogênico mais frequentemente isolado de leite cru (ZECCONI; HAHN , 2001) e em quadros de mastite (SILva et al. 2000). De acordo com a WHO (World Health Orgazization,1995), este micro-organismo é o maior responsável pelo aumento na Contagem de Células Somáticas (CCS) no leite, o que acarreta redução na produtividade e comprometimento na composição nutricional do leite (ASPERGER, 1994).

Os estafilococos, na maioria das vezes, atingem a glândula mamária através da superfície de tetos higienizados inadequadamente, equipamentos e utensílios de ordenha contaminados, mãos de manipuladores e ordenhadores (ASPERGER, 1994). AmAral et al. (2003) verificaram o papel da água utilizada durante a produção do leite como via de transmissão de Staphylococcus sp. em 30 propriedades leiteiras situadas na região Nordeste do Estado de São Paulo. As maiores ocorrências de isolamentos $(10,0$ e $16,6 \%)$ e os maiores valores médios $\left(4,3 \times 10^{4}\right.$ e $2,5 \times 10^{4} \mathrm{UFC} / \mathrm{mL}$ ) de contagens desses microorganismos foram encontrados nas amostras de água dos estábulos utilizada na obtenção de leite. OLIVINDOet al. (2009) aplicaram a técnica de REP-PCR no monitoramento da qualidade do leite de cabra por meio da detecção de $S$. aureus em amostras de mãos de ordenhador, tetos das cabras, leite, ordenhadeira e água. Os autores observaram comportamentos muito similares das bandas, o que indica que os isolados podem ser relatados como clones epidemiológicos. As mãos do ordenhador caracterizaram-se como iniciador de contaminação nas amostras $S$. aureus.

BRITO et al. (1998), em Juiz de Fora, MG, ao analisarem 33 rebanhos de gado de leite da região, cujas amostras foram obtidas na plataforma de recepção da indústria, isolaram S. aureus em $26(78,8 \%)$ amostras. BoRGES et al. (2008) avaliaram a contaminação por $S$. aureus de uma linha de produção de queijo coalho e encontraram nas amostras de leite cru $100 \%$ das amostras positivas para estafilococos coagulasepositiva, sendo que a presença da EE foi detectada em $20 \%$ das amostras analisadas.

Em municípios de Minas Gerais, de 127 amostras de cepas de $S$. aureus isoladas de casos de mastites, $60(47 \%)$ delas produziram pelo menos um dos tipos de enterotoxinas testadas (TSST-1, EEA, EEB, EEC e $\mathrm{EEE})$, sendo algumas cepas produtoras de até quatro delas (CARDOSO et al., 2000). NormANo et al.(2005) analisaram 3.097 amostras de leite e derivados e encontraram 20,7\% das amostras como ECP. Dos ECP isolados, 364 cepas foram para identificação e 362 foram identificadas como S. aureus, onde $59,9 \%$ eram enteroxigênicos e a maioria produtores de EEC. CARVALHO et al. (2002), ao analisarem S. aureus recuperados de 31 amostras de leite in natura e de 64 alimentos envolvidos em intoxicações alimentares, encontraram a quase totalidade das amostras, positivas para a produção de ao menos uma das EE testadas, sendo Toxina da Síndrome do Choque Tóxico (TSST-1) mais frequente em leite $(87,10 \%)$ e Enterotoxina Estafilocócica B (EEB) prevalecendo nas amostras dos surtos (65,63\%). Em um estudo rea lizado em Trinidade e Tobago, 45 (42,9\%) das cepas isoladas de tanques de estocagem eram produtoras de uma ou mais das enterotoxinas testadas (EEA, EEB, EEC e EED), 69 (47,3\%) cepas do leite de tanques de conjunto e $66(45,2 \%)$ daquelas isoladas de mãos de ordenhadores seguiam as mesmas características enterotoxigênicas do primeiro resultado (ADESYUNet al.,1998). CENCI-Goga et al. (2003) isolaram 160 cepas de $S$. aureus de animais com mastite, oriundas de 18 propriedades na Califórnia (EUA), e encontraram $22(14 \%)$ cepas como produtoras de EE, sendo 7 produtoras de EEC, 12 de EED e 3 de EEC e EED.

Os alimentos envolvidos em surtos de intoxicação por ingestão de toxina estafilocócica variam nos diversos países e em diferentes regiões de um mesmo país, devido às diferenças nos hábitos alimentares (LOIR et al., 2003, WONG; BERGDOLL , 2002). Na França, por exemplo, o principal alimento envolvido nos quadros de intoxicação por estafilococos entre 19992000 foram os derivados lácteos, principalmente os queijos, sendo responsáveis por $32 \%$ dos casos (LoIR et al., 2003). BuYsER et al. (2001), em sua revisão sobre surtos de intoxicação alimentar na França entre os anos de 1988 e 1997, relataram que leite e derivados foram incriminados em 177 surtos de toxinfecções alimentares $(4,6 \%)$, sendo o $S$. aureus envolvido em $59 \%$ dos surtos. De maneira geral, o leite cru e derivados, creme, tortas recheadas com creme, salada de batata, atum, carne de frango, presunto, carnes e produtos à base de ovos estão envolvidos em surtos alimentares causados por este patógeno em questão (Franco; Landgraf, 2005; Loir et al., 2003; Pereira et al., 2001; BREWER , 1991).

Nos EUA, os surtos de intoxicação alimentar em escolas, reportados ao CDC, incriminam alimentos contendo carne $(18,6 \%)$, saladas $(6 \%)$, comidas mexicanas $(6 \%)$, bife $(5,7 \%)$ e produtos lácteos como oleite e queijos (5\%). Nessas escolas foi também relatado que, entre os anos de 1988 e 1992, do total de 465 surtos de intoxicação onde o alimento foi identificado, em 2,2\% o leite e derivados foram incriminados (DANIELS et al., 2002). Na Inglaterra e País de Gales, entre 1992 e 1993, 204 alimentos foram envolvidos em surtos, sendo o leite e derivados associados a 4,4\% destes e, na Alemanha (1993-1996), do total de 547 casos, 5,5\% tiveram o leite e seus derivados como responsáveis porcasos de intoxicação alimentar (BUYSERetal.,2001).

Os alimentos que requerem considerável manipulação para seu preparo, que permanecem em 
temperatura ambiente elevada e por longo tempo após sua preparação são, geralmente, considerados de alto risco (CENTER for Diseases Control, 2003). Segundo Roberts (1990), os quadros de intoxicação por $S$. aureus estão associados a comidas frias muito manipuladas durante a preparação e produtos lácteos, especialmente aqueles preparados a partir de leite cru.

\section{SINTOMATOLOGIA}

Operíodo de incubação e a sintomatologia variam com a sensibilidade individual e a quantidade de toxina no alimento ingerido (FRANCO; LANDGRAF, 2005). Os principais sintomas são náuseas, vômito, cãibras abdominais e diarreia. Quadros febris são incomuns e, quando presentes, normalmente estão associados à ingestão de grandes quantidades de toxina. O período de incubação varia de 15 minutos a 8 horas, sendo em média 2 a 4 horas (LoIR et al.,2003; Wong; Bergdoll , 2002; Dinges et al., 2000; Su; WonG, 1997; LANCETTE; TATINI, 1992; EVENSON etal.,1988). A cura espontânea é comum, ocorrendo após 24 horas (LoIR et al., 2003) e a recuperação completa entre 1 e 3 dias (Su; Wong, 1997). Os sintomas muitas vezes se confundem com os de outros patógenos causadores de DTA, como é o caso de Bacillus cereus que também causa um quadro intenso de vômito (U.S. FoOD AND Drug Admistration, 1992).

\section{PRODUÇÃO DE ENTEROTOXINAS}

Os diferentes tipos de enterotoxinas produzidas pelos estafilococos foram inicialmente descritos por BERGDOLl et al., em 1973, como sendo 5 tipos sorologicamente distintos, denominados de EEA, EEB, EEC1, EEC2, EEC3, EED e EEE. Na sequência, novas enterotoxinas e seus genes correspondentes foram descritos embora seu envolvimento com os surtos deintoxicação alimentar não estejam ainda bem esclarecidos. Estas novas EE foram denominadas EEG, EEH, EEI, EEJ, EEK, EEL, EEM, EEN, EEO, EEP, EEQ, EER e EEU (JORGENSEN et al., 2005). O International Nomenclature Committee for Staphylococcal Superantigen Nomenclature (INCSSN) recomendou que apenas os superantígenos estafilocócicos que induzem vômito após administração oral experimental em macacos pode ser designado como EE. Aqueles que não promovem emese no modelo experimental designado ou não foram testados devem receber a denominação de staphylococcal enterotoxin-like (SEI). Desta forma as enterotoxinas dos tiposSEJ,SEK,SEL,SEM,SEN,SEO, SEP, SEQ e SEU deveriam ser renomeadas para SEIJ, SEIK, SEIL, SEIM, SEIN, SEIO, SEIP, SEIQ e SEIU, respectivamente (OMOE et al., 2005).

As enterotoxinas estafilocócicas são proteínas simples de baixo peso molecular (27,5 a 30,0 KDA) e suas cadeias polipeptídicas apresentam quantidades apreciáveis de lisina, acido aspártico, ácido glutâmico e tirosina. A composição dos aminoácidos das EEA, EED e EEE são similares, o mesmo ocorrendo com EEB e EEC. Estas proteínas são resistentes à tripsina, quimotripsina, renina, papaína e pepsina, o que possibilita a sua passagem pelo trato gastrointestinal. Apenas a EEB é inativada pela pepsina em pH próximo de 2.0. As enterotoxinas ainda são termorresistentes, o que aumenta sua importância na indústria de alimentos uma vez que a maioria dos alimentos recebe tratamento térmico (WONG; BERGDOLL , 2002; FRANCO; LANDGRAF, 2005; AsPERGER, 1994). O grau de resistência das enterotoxinas depende de vários fatores como o tipo de enterotoxina, $\mathrm{pH}$ e o meio. As EEs quando purificadas tornam-se mais termossensíveis que as não purificadas, enquanto que a inativação por tratamento térmico é mais rápida em soluções tampão que em meios de cultura e alimentos (WonG; BERGDOLL , 2002).

A produção de enterotoxinas é influenciada pela temperatura, pH, aw, tamanho do inóculo, fonte de carbono enitrogênio, concentração de sal e condições atmosféricas do substrato. Em temperaturas ótimas, a enterotoxina torna-se detectável entre 4 a 6 horas (FRANCO; LANDGRAF, 2005; WonG; BERGDOLL , 2002). Os alimentos expostos a temperaturas mais elevadas apresentam um maior potencial à produção de enterotoxinas pelos estafilococos, em especial alimentos fermentados e lácteos (LANCETTE; TATini , 1992). A manutenção em baixas temperaturas pode ser usada no controle da produção de enterotoxinas em alimentos, pois a multiplicação bacteriana diminui e a síntese de enterotoxinas é quase totalmente inibida em temperaturas inferiores a $7^{\circ} \mathrm{C}$ (ASPERGER, 1994). Segundo BERGDOLL, 1983 (apud LoIr et al., 2003), as enterotoxinas são mais termorresistentes em alimentos que em meios de cultura, podendo ser inativadas através do tratamento térmico como a esterilização no caso de alimentos enlatados, quando em baixas concentrações no alimento. Para a inativação da toxina seriam necessários de 3 a 8 minutos a $121^{\circ} \mathrm{C}$ (BAIRD-PARKER , 1990). Segundo FDA (U.S. FOOD AND Drug Admistration, 2001), a toxina estafilocócica é sensível entre $98,9^{\circ} \mathrm{C}$ por 68,5 min e $126,7^{\circ} \mathrm{C}$ por 6,2 minutos. A produção de EE é ideal em pH neutro, sendo o pHácido desfavorável, ocorrendo a inibição de síntese de enterotoxinas em pH menor que 5.0. Por outro lado, $\mathrm{pHs}$ alcalinos levam a diminuição da síntese de EEB, EEC e EED (LoIr et al., 2003).

As enterotoxinas A e D são produzidas em condições amplas de pH, aw e Eh, diferentes da EEB e EEC que, quando em condições de $\mathrm{pH}$ abaixo do ideal, são o produzidas em maior quantidade que as primeiras (WONG; BERGDOLL , 2002; ZOLI et al., 2002). Sabe-se que em meio de cultura as enterotoxinas B e Csão produzidas em maiores quantidades (>100ug/ 
$\mathrm{mL}$ ) do que outras como a EEE e EED, sendo a EEH normalmente produzida em quantidades menores que $1 \mathrm{ug} / \mathrm{mL}$ (WONG; BERGDOLL , 2002).

A maioria das intoxicações é produzida principalmente pela ingestão de EEA e EED (ZoLi et al., 2002; Fey et al., 1984), sendo necessário também uma quantidade menor de micro-organismos para a sua produção, quando comparadas aos outros tipos de EEs (WONG; BERGDOLL , 2002; Zoliet al., 2002). Segundo KOKAN; BERGDOLL (1987), as cepas produtoras de EED são responsáveis pela maior parte dos surtos de intoxicação estafilocócica, principalmente aqueles onde o alimento envolvido é o leite. Nos casos de mastite estafilocócica, a enterotoxina mais frequentemente produzida é a EEC (WILson et al., 1991). Mas recentemente foram descritos outros tipos de EEs (EEG a $\mathrm{EEJ}$ ) em casos de mastite, resultados estes ainda não bem esclarecidos (KaTsuda et al., 2005).

As EEs são detectáveis nos alimentos apenas quando as contagens de $S$. aureus ultrapassam $10^{5}$ UFC/mL ou g de alimento (WONG; BERGDOLL , 2002; LANCETTE; TATINI , 1992; PARK et al., 1992). Segundo ASPERGER (1995), $10^{5}$ pode ser usado comoquantidade mínima para detecção de EE, embora em pesquisas laboratoriais tenha-se observado que só é possível a detecção de enterotoxinas em contagens de $S$. aureus acima de $10^{6}$ UFC. Na maioria dos alimentos associados às intoxicações, contagens de $10^{8}$ ou valores superiores são raramente relatados.

Segundo Wong; Bergdoll (2002), S. aureus é relativamente resistente à dessecação, ocorrendo desta forma surtos de intoxicação com leite em pó e alimentos contendo este produto. No Egito, no ano de 1986, o leite em pó foi incriminado em surtos de intoxicação detectando-se 0,125 ug de EEA e 1,5 ug de EEB (El Dairouty, 1989), com ausência de estafilococos coagulase positiva e outros patógenos e contagens totais de micro-organismos entre $7,9 \times$ $10^{2}$ e $5 \times 10^{4}$ células/g. Em 2000, em um surto no Japão, por ingestão de leite em pó reconstituído, detectou-se em média 3,7 ng de EEA/g de alimento (IKEDA et al., 2005).

Várias condições são necessárias para que ocorra produção de enterotoxina em alimentos, dentre as principais que o alimento forneça condições para o crescimento bacteriano, como tempo e temperatu$\mathrm{ra}$, e que as cepas presentes tenham característica enterotoxigênica (WONG; BERGDOLL , 2002; AsPERGER ,1994). Segundo Oliveira et al. (1994), o problema de contaminação dos alimentos está associado à falhas na manipulação ou na conservação como cozimento ou descongelamento incorreto, aproveitamento de sobras e equipamentos higienizados incorretamente.

No diagnóstico de um surto de intoxicação alimentaréimportanteque sejam utilizadas entrevistas, análises epidemiológicas e métodos sorológicos para verificação da capacidade enterotoxigênica do
S. aureus isolado do alimento envolvido (U.S. FooD and Drug Admistration, 1992). A presença de um grande número de estafilococos em um alimento não é suficiente para incriminar o agente e o alimento como responsável por um surto e, ainda, a ausência do patógeno não o exclui como causador do surto. É preciso que para isso se determine o potencial enterotoxigênico dos estafilococos e/ou a presença da enterotoxina no alimento (LANCETTE; TATINI, 1992).

\section{PESQUISA DE ENTEROTOXINA}

Historicamente, a primeira investigação sobre intoxicação estafilocócica ocorreu em 1914 onde, após algumas visitas a propriedades leiteiras e ingestão de leite cru, Dr. Barber apresentou sintomas da doença, isolando, em suas pesquisas posteriores, o micro-organismo do leite. Em 1929, houve uma redescoberta da intoxicação estafilocócica com um trabalho clássico publicado, onde dois doces de Natal foram responsáveis pela intoxicação de 11 pessoas. O micro-organismo foi isolado e o sobrenadante da centrifugação foi testado em voluntários, que apresentaram a mesma sintomatologia (WONG; BERGDOLL , 2002).

O diagnóstico da intoxicação estafilocócica é feito basicamente por dois aspectos: sintomatologia e presença da EE no alimento (NAJERA-SANCHES et al., 2003). A confirmação da presença de enterotoxinas estafilocócicas para elucidação dos surtos era conduzida por métodos biológicos, que consistiam na administração da toxina por via gástrica em macacos e por via intraperitonial ou intravenosa em gatos (Pereira et al., 2001; Pereira et al., 2000). Esses métodos eram pouco sensíveis, com diferenças de suscetibilidade entre os macacos e reações não específicas em gatos, sendo esses problemas os principais fatores que levaram ao desenvolvimento de outros métodos de diagnóstico (Su; WonG, 1997). A partir da identificação das proteínas enterotoxigênicas, por BERGDOLL et al. (1959), as técnicas de detecção fundamentaram-se no uso de anticorpos preparados contra as enterotoxinas, uma vez que as toxinas apresentavam-se como proteínas simples, não passíveis, portanto, de detecção por métodos químicos ( Pereira et al., 2001).

A dose mínima para causar um surto de intoxicação estafilocócica não está bem esclarecida, mas com base nos dados de surtos e estudos, sabe-se que o consumo mínimo de 100 ng de EE já pode causar um quadro de intoxicação em indivíduos suscetíveis (U.S. FoOD AND Drug Admistration,1992; LANCETTE; TATINI , 1992; KOKAN; BERgDOlL , 1987). De acordo com AsPerger (1994), a dose mínima para causar sintomatologia pode variar entre 100 e 1.000 ng. A dificuldade na determinação da dose emética está relacionada com a análise do alimento, pois, na 
maioria dos surtos, a enterotoxina não está uniformemente distribuída no alimento e há dificuldade de se avaliar quanto o indivíduo ingeriu do alimento (WONG; BERGDOLL , 2002). Zoli et al. (2002) relataram que a quantidade de toxina presente em alimentos envolvidos em surtos varia de menos $1 \mathrm{ng}$ a $1 \mathrm{mg} / \mathrm{g}$, destacando-se a importância da sensibilidade dos testes para detecção direta da enterotoxina em alimentos. ZECCONI; HAHN (2001) estimaram que em $50 \mathrm{~g}$ de queijo feito com leite cru contaminado com $S$. aureus, a dose tóxica varia entre 0,1 e $1 \mathrm{mg}$. De acordo com WonG; BERGDOLL (2002), a quantidade de enterotoxina presente nos alimentos é geralmente pequena, variando entre 10 e $50 \mathrm{ng} / \mathrm{g}$ de alimento, o que não resulta em morte do indivíduo.

Para detecção de enterotoxina estafilocócica, vários métodos foram desenvolvidos como os biológicos e os imunológicos. Os métodos imunológicos são mais sensíveis e específicos (Su; WoNG, 1997) e utilizam anticorpos monoclonais e policlonais específicos para identificação das EEs (LANCETTE; TATINI, 1992). De acordo com LANCETTE; TATINI (1992), o maior problema na identificação da enterotoxina estafilocócica em alimentos é a pequena quantidade queé encontrada no alimento incriminado em surtos de intoxicação alimentar.

O primeiro teste sorológico desenvolvido foi o método de imunodifusão baseado na reação em gel da enterotoxina com anticorpo específico, formando uma linha de precipitação (WONG; BERGDOLL , 2002; Su; Wong, 1997). A técnica de Sensibilidade Ótima em Placas (OSP-Optimum Sensitivy Plate) permite a detecção de 0,5 ug deEE/mL, sendo sua sensibilidade adequada para maioria das cepas enterotoxigênicas (Wong; Bergdoll , 2002; Pereira et al., 2001;Su; Wong, 1997; ROBBINS et al., 1974), não sendo possível detectar linhagens pouco produtoras (BERGDOLL , 1990). A utilização de técnicas de produção e concentração como cellophane-over-agar podeaumentar a sensibilidade para 0,1 ug/mL (WONG; BERGDOLL , 2002; CunHa et al., 1996). A técnica de OSP foi desenvolvida com o objetivo de promover um teste com maior sensibilidade, de maneira a não comprometer a visualização da linha de precipitação. Sabe-se que fatores como o tipo e a concentração do ágar, quantidade distribuída na placa, tamanho e localização dos poços e a concentração do antissoro e toxina podem influenciar na sensibilidade e resolução do teste (RobBinsetal.,1974). O método de imunodifusão em microlâminas (microslide) é o mais sensível na imunodifusão em gel, tendo a capacidade de detectar de 0,05 a 0,1 ug/mL, embora apresente resultados de difícil interpretação (WONG; BERGDOLL , 2002).

O método imunológico atualmente mais empregado para detecção de enterotoxina estafilocócica é a técnica de ELISA (Enzyme-Linked Immunosorbent Assay). Outro ensaio imunológico é a técnica de Aglutinação Reversa Passiva em Látex (RPLAReversed Passive Latex Agglutinations) baseada em anticorpos específicos aderidos a partículas de látex, apresentando uma sensibilidade de $1 \mathrm{ng} / \mathrm{mL}$ (Wong; Bergdoll, 2002).

Vários tipos de ELISA foram desenvolvidos, sendo o ELISA sanduíche o método mais comum (SAntos, 2003; Wong; Bergdoll, 2002; Su; Wong, 1997), podendo detectar menos de $1 \mathrm{ng}$ de EE por mL de sobrenadante (FREED et al., 1982). Essa técnica é a mais adequada para detecção de enterotoxinas estafilocócicas em alimentos, pois o desenvolvimento de cor é diretamente proporcional à quantidade de enterotoxina presente na amostra, além de não necessitar de enterotoxinas altamente purificadas para o preparo da curva padrão (SANTOS, 2003; WONG; BERGDOLL, 2002). Segundo FDA (U.S. FoOD AND DRUG Admistration, 2001), a técnica de ELISA é sensível, simples, rápida e disponível em kits comerciais com anticorpos distintos, policlonais ou monoclonais (Su; Wong , 1997). Segundo SAnTos (2003) e LANCETTE; TATINI (1992), apesar de a técnica ser rápida e sensível, pode apresentar falsos positivos devido às reações inespecíficas, principalmente com a proteína A. Quando se trata de alimentos que passaram por tratamentos térmicos pode haver resultados falso negativos, pois as enterotoxinas podem estar agregadas, reduzindo a reação com o anticorpo (U.S. Food And Drug Admistration, 2001). Para pesquisa de enterotoxina em alimentos, uma série de kits comerciais são usados, sendo a maioria baseada na técnica de ELISA e com sensibilidade variando entre 0,1 e $1 \mathrm{ng} / \mathrm{mL}$ (Su;Wong, 1997).

O desenvolvimento das técnicas moleculares permitiu a utilização de uma nova ferramenta para detecção da sequência de nucleotídeos do gene, responsável pela produção de enterotoxina pelos estafilococos. Técnicas como a Reação em Cadeia da Polimerase (PCR) pode ser aplicada para detecção de diversos tipos de estafilococos enterotoxigênicos em culturas e alimentos. São conhecidos pelo menos quatro sistemas regulatórios que afetam a expressão de proteínas extracelulares ou de superfície celular, sendo o principal sistema regulatório dos fatores de virulência no $S$. aureus o gene acessório regulador (agr), que atua em combinação com o acessório regulador estafilococal (sar), envolvidos em um complexo sistema global regulatório. A maioria dos genes EE é controlada pelo sistema agr. Os genes seb, sec e sed têm sido demonstrados como agr dependentes, enquanto os sea e sej como agr independentes (LOIR et al., 2003; WONG; Bergdoll , 2002). A produção do agr-dependente em alimentos está relacionada com a capacidade da população de $S$. aureus em atingir uma população em torno de $10^{6} \mathrm{UFC} / \mathrm{g}$ ou $\mathrm{mL}$, sendo os fatores ambientais de grande importância na sua expressão (LoIR et al., 2003). 
A técnica dePCRéaltamente sensível eespecífica, permitindo a deteç̧ão dos micro-organismos em período relativamentecurto a partir de uma pequena amostra. (Su; WONG, 1997). A pesar dessas vantagens, não é possível a diferenciação entre células viáveis e inviáveis. Dessa forma o resultado positivo para a presença do micro-organismo não necessariamente indicará a presença de células viáveis produtoras de EE na amostra de alimento (WONG; BERGDOLL, 2002; Su; WONG, 1997), não sendo o diagnóstico final conclusivo.

\section{CONCLUSÃO}

Desta forma, entende-se que os estafilococos são um patógeno de importância dentro das DTAs, tornando necessárias mais informações epidemiológicas a respeito dos surtos envolvendo esse micro-organismo. Falhas no diagnóstico clínico e laboratorial são muitas vezes o principal motivo para as subnotificações a respeito das intoxicações alimentares no país.

\section{REFERÊNCIAS}

ADESYUN, A.A.; WEBB, L.A.; ROMAIN, H.T. Prevalence and characteristic of Staphylococcus aureus strains isolated from bulk and composite milk and cattle handers. Journal of Food Protection, v.61, n.5, p.629-632, 1998.

AKINEDEN, O.; ANNEMULLER, C.; HASSAN, A.A.; LAMMLER, C.; WOLTER, W.; ZSCHOCK, M. Toxin genes and other characteristics of Staphylococcus aureus isolates from milk of cows with mastitis. Clinical and Diagnostic Laboratory Immunology, v.8, n.5, p.959-964, 2001.

AMARAL, L.A.; ROSSI JÚNIOR, O.D.; NADER FILHO, A.; FERREIRA, F.L.A.; BARROS, L.S.S. Ocorrência de Staphylococcus sp. em água utilizada em propriedades leiteiras do Estado de São Paulo. Arquivo Brasileiro de Medicina Veterinária e Zootecnia, v.55, n.5, p.620-623, 2003.

ASPERGER, H. Staphylococcus aureus. In: INTERNATIONAL DAIRY FEDERATION. Group of Experts A10/11. The significance of pathogenic microorganisms in raw milk. Brussels: IDF, 1994. p.24-42. (Special Issue, 9405).

BAIRD-PARKER, A.C. The staphylococci "an introduction". Journal of Applied Bacteriology, p.1S-8S, 1990. Supplement.

BERGDOLL, M.S. Analytical methods for Staphylococcus aureus. International Journal of Food Microbiology, v.10, p.91-100, 1990.

BERGDOLL, M.S.; SURGALLA, M.J.; DACK, G.M. Staphylococcal enterotoxin. Identification of a specific precipitating antibody with enterotoxinneutralizing property. Journal of Immunology, v.83, p.334-338, 1959.

BERGDOLL, M.S.; ROBBINS,R.N.;WEISS,R.N.;BORJAC .R.; HUANG, Y.; CHU, F.S. The staphylococcal enterotoxins. Contributions to Microbiology and Immunology, v.1, p.390-396, 1973.

BORGES, M.F.; NASSU, R.T.; PEREIRA, J.L; ANDRADE, A.P.C.; KUAYE, A.Y. Perfil da contaminação por estafilococos e suas enterotoxinas e monitorização das condições de higiene em uma linha de produção de queijo de coalho. Ciência Rural, v.38, n.5, p.1434-1438, 2008.

BREWER, M.S. Food storage, food spoilage, and foodborne illness. Urbana, Illinois: Phyllis Yates Picklesimer, 1991. $19 \mathrm{p}$.

BRITO, M.A.V.P.; BRITO, J.R.F.; SOUZA, H.M.; VARGAS, O.L. Avaliação da sensibilidade da cultura de leite do tanque para isolamento de agentes contagiosos da mastite bovina. Pesquisa Veterinária Brasileira, v.18, n.1, p.39-44, 1998.

BUYSER, M.L. de; DUFOUR, B.; MAIRE, M.; LAFARGE, $\mathrm{V}$. Implication of milk and milk products in foodborne diseases in France and in different industrialized countries. International Journal of Food Microbiology, v.67, p.1-17, 2001.

CARDOSO, H.F.T.; CARMO, L.S.; SILVA, N. Detecção da toxina 1 da síndrome do choque tóxico em amostras de S. aureus isoladas de mastite bovina. Arquivo Brasileiro de Medicina Veterinária e Zootecnia, v.52, n.1, p.7-10, 2000.

CARMO, L.S. Produção e purificação em grande escala das enterotoxinas estafilocócicas SEA, SEB, SEC2, SED e TSST-1 para uso em ensaios imuno-enzimáticos. 2001. 254f. Tese em Microbiologia) - Instituto de Ciências Biológicas, Universidade Federal de Minas Gerais, Belo Horizonte, 2001.

CARMO, L.S. Revista Minas Faz Ciência, n.11, jun/ago., 2002. Disponível em: <http://revista.fapemig.br.htm>. Acesso em: 9 mai. 2005.

CARVALHO, S.A.; CARVALHO, M.A.R.; CARMO, L.S.; DIAS, R.S.; ABREU, E.F.; BRAGA, R.G. Pesquisa de enterotoxinas e de substâncias antagonistas produzidas por Staphylococcus aureus recuperados de leite bovino in natura e de outros alimentos. In: SEMANA DE PÓS GRADUAÇÃO DA UFMG, 3., Belo Horizonte, 2002. Anais. Belo Horizonte, 2002.

CENCI-GOGA, B.T.; KARAMA, M.; ROSSITO, P.V.; MORGANTE, R.A.; CULLOR, J.S. Enterotoxin production by Staphylococcus aureus isolated from mastitic cows. Journal of Food Protection, v.66, n.9, p.1693-1696, 2003. 
CENTER FOR DISEASES CONTROL (US). 2000. Surveillance for Foodborne-Disease Outbreaks - United States, 1993-1997 Disponível em: <http:/www.ers.usda.gov/ briefing/foodborneDisease.htm>. Acesso em: 20 jan. 2006.

CENTER FOR DISEASES CONTROL (US). 2009. Food Safety. Disponível em: <http:/www.cdc.gov/briefing/ fncidod/eid/voln05/mead.htm>. Acesso em: 23 mar. 2009.

CENTRO DE VIGILÂNCIA EPIDEMIOLÓGICA. (São Paulo). 2003. Disponível em: <http:/www.cve.saude. sp.gov.br/htm/hídrica/saphylo.htm>.Acesso em: 9 mai. 2005.

CUNHA, M.L.R.S.; OLIVEIRA, T.C.R.M.; HIROOKA, Y.E. Generalidades sobre enterotoxinas estafilocócicas em alimentos. Revista de Ciências Farmacêuticas, v.17, p.9-22, 1996.

DANIELS, N.A. MACKINNON, L.; ROWE, S.M.; BEAN, N.; GRIFFIN, P.; MEAD, P.S. Foodborne disease outbreaks in United States schools. The Pediatric Infectious Diseases Journal, v.21, n.7, p.623-627, 2002.

DINGES, M.M.; ORWIN, P.M.; SCHLIEVERT, P.M. Exotoxins of Staphylococcus aureus. Clinical Microbiology Review, v.13, p.16-34, 2000.

EL DAIROUTY, K.R. Staphylococcal intoxication traced to non-fat dried milk. Journal of Food Protection, v.52, p.901-902, 1989.

EVENSON, M.L.; HINDES, M.W.; BERNSTEIN, R.S. Estimation of human dose of staphylococcal enterotoxin A from a large outbreak involving chocolate milk. International Journal of Food Microbiology, v.7, p.311-316, 1988.

FEY, H.; PFISTER, H.; RUEGG, O. Comparative evaluation of different enzyme-linked immunosorbent assay systems for the detection of staphylococcal enterotoxins A, B, C and D. Journal of Clinical Microbiology, v.19, n.1, p.34-38, 1984.

FRANCO, B.D.G. de M.; LANDGRAF, M. Microbiologia dos alimentos. São Paulo: Editora Atheneu, 2005.

FREED, R.C.; EVENSON, M.L.; REISER, R.F.; BERGDOLL, M.S. Enzyme-linked immunoabsorbent assay for detection of staphylococcal enterotoxins in foods. Applied and Environmental Microbiology, v.44, n.6, p.1349-1355, 1982.

IKEDA, T.; TAMATE, N.; YAMAGUCHI, K.; MAKINO, $\mathrm{S}$. Mass outbreak of food poisoning disease caused by small amounts of staphylococcal enterotoxins A and H. Applied and Environmental Microbiology, v.71, p.27932795, 2005.

INSTITUTO PANAMERICANO DE PROTEÇÃO DOS ALIMENTOS E ZOONOSES. 2002. Disponível em: <http:/www.panalimentos.org/sirveta/e/salida2.asp. htm>. Acesso em: 3 set. 2005.
JORGENSEN,H.J.; MORK,T.;HOGASEN, H.R.; RORVIK, L.M. Enterotoxigenic Staphylococcus aureus in bulk milk in Norway. Journal of Applied Microbiology, v.99, p.158-166, 2005.

KATSUDA, K.; HATA, E.; EGUCHI, M. Molecular typing of S.aureus isolated from bovine mastitic milk on the basic of toxin genes and coagulase gene polymorphisms. Veterinary Microbiology, v.105, p.301-305, 2005.

KOKAN, N.P.; BERGDOLL, M.S. Detection of low enterotoxina producing Staphylococcus aureus strains. Applied and Environmental Microbiology, v.53, n.11, p.2675-2676, 1987.

LANCETTE, G.A.; TATINI, S.R. Staphylococcus aureus. In: VANDRZANT, C. (Ed.). Compendium of methods for the microbiological examination of foods. 3.ed. Washington: American Public Health Association, 1992.

LOIR, Y. LE; BARON, F.; GAUTIR, M. Staphylococcus aureus and food poisoning. Genetic Molecular Research, v.2, n.1, p.63-76, 2003.

MEER, R.; MISNER, S. What is a food-borne illness? Arizona Cooperative Extension, University of Arizona, 5/1999. AZ1065. Disponível em: <http//:ag.arizona. edu/pubs/health/az1065.pdf>. Acesso em: 3 set. 2005.

NAJERA-SANCHES, G.; MALDONADO-RODRIGUEZ, R.; OLVERA, P.R.;GARZA, L.M. Development of two multiplex plymerase Caín reactions for the detection of enterotoxigenic strains of Staphyloccus aureus isolated from foods. Journal of Food Protection, v.66, n.6, p.10551062, 2003.

NORMANO, G.; FIRINU, A.; VIRGILIO, S.; MULA, G.; DAMBROSIO, A.; MIONI, R.;SALINETTI, A.P.; SALANDRA, A.LA; PARISI, A.; QUAGLIA, N.C.; CELANO, G.V. Coagulase-positive Staphylococci and Staphylococcus aureus in food products marketed in Italy. International Journal of Food Microbiology, v.98, p.73-79, 2005.

OLIVEIRA, T.C.R.M.; LEE, H.; WYATT, G.; HIROOKA, E.; MORGAN, M.R.A. A simple and rapid antibody capture ELISA for the detection of staphylococcal enterotoxin A in food including a simple extraction step. International Journal of Food Science and Technology, v.29, p.563-573, 1994.

OLIVINDO, C. S.;CHAPAVAL, L.;VILLARROEL, A.B.S.; ALVES, F.S.F.;SOUSA, F.G.C.; FERNANDES, F.E.P. Detecção de Staphylococcus aureus utilizando a técnica de REP-PCR no monitoramento da qualidade do leite de cabra. Revista Brasileira de Zootecnia, v.38, n.7, p.1317-1321, 2009.

OMOE, K.; HU, D-L.; TAKAHASHI-OMOE, H.; NAKANE, A.; SHAINAGAWA, K. Comprehensive analysis of classical and newly described staphylococcal superantigenic toxin genes in Staphylococcus aureus 
isolates. FEMS Microbiology Letters, v.246, p.191-198, 2005.

ORDEN, J.A.; GOYACHE, J.; HERNANDEZ, J.; DOMENECH, A. SUAREZ, G.; GOMEZ-LUCIA, E. Production of staphylococcal enterotoxins and TSST-1 by coagulase negative staphylococci isolate from ruminant mastitis. Journal of Veterinary Medicine, v.39, p.144-148, 1992.

PARK, C.E.; AKTAR, M.; RAYMAN, K. Nonespecific reactions of a commercial enzyme-linked immunoabsorbent assay kit (tecra) for detection of staphylococcal enterotoxinas in foods. Applied and Environmental Microbiology, v.58, n.8, p.2509-2512, 1992.

PEREIRA, M.L.; CARMO, L.S.; SANTOS, E.J.; BERGDOLL, M.S. Staphylococcal food poisoning from creamfilled cake in a metropolitan area of South-Eastern Brazil. Revista de Saúde Pública, v.28, n.6, p.406-409, 1994.

PEREIRA, M.A.; PEREIRA, J.L.; SERRANO, A.M.; BERGDOLL, M.S. Estafilococos: Até onde sua importância em alimentos? Higiene Alimentar, v.14, n.68, p.32-39, 2000

PEREIRA, M.L.; CARMO, L.S.; PEREIRA, J.L. Comportamento de estafilococos coagulase negativos pauciprodutores de enterotoxinas em alimentos experimentalmente inoculados. Ciência e Tecnologia de Alimentos, v.21, n.2, p.171-175, 2001.

ROBERTS, D. Sources of infection: foods. The Lancet, v.336, p.859-861, 1990.

\section{ROBBINS, R.N.; GOULD, S.; BERGDOLL,}

M.S.Detecting the enterotoxigenity of Staphylococcus aureus strains. Applied Microbiology, v.28, p.946-950, 1974.

SANTOS, A. Estudo comparativo entre a PCR e técnicas imunológicas (ELISA, RPLA e OSP) na enterotoxigenicidade de isolados de estafilococos coagulase negativa. 2003. 77f. Dissertação (Mestrado em Ciência dos Alimentos) - Departamento de Tecnologia de Alimentos e Medicamentos, Universidade Estadual de Londrina, Londrina, 2003.

SILVA, W.P.; DESTRO, M.T.; LANDGRAF, M.; FRANCO, B.D.G.M. Biochemical characteristics of typical and atypical Staphylococcus aureus in mastitic milk and environmental sample of brazilian dairy farms. Brazilian Journal of Microbiology, v.3, p.103-106, 2000.

SU, Y.-C.; WONG, A.C.L. Current perspectives on detection of staphylococcal enterotoxins. Journal of Food Protection, v.60, n.2, p.195-202, 1997.

US. DEPARTMENT OF AGRICULTURE. Economic Research Service. 2001. A Safe Food Supply. Disponível em: <http:/www.ers.usda.gov/briefing/foodborneDisease/foodandpathogens.htm>. Acesso em: 20 jan. 2006.
US. DEPARTMENT OF AGRICULTURE. Economic Research Service. 2004. A Safe Food Supply. Disponível em: <http:/www.ers.usda.gov/briefing/foodborneDisease/ foodandpathogens.htm>. Acesso em: 20 jan. 2006.

\section{U.S. FOOD AND DRUG ADMINISTRATION. Center} for Food Safety and Applied Nutrition. Foodborne Pathogenic Microorganisms and Natural Toxins Handbook. 1992.

U.S. FOOD AND DRUG ADMINISTRATION. Center for Food Safety And Applied Nutrition.Bad Bug Book: Foodborne Pathogenic Microorganisms and Natural Toxins Handbook Staphylococcus aureus. Disponível em: $<$ http:/www.cfsan.fda.gov/ mow/chap3.htm>. Acesso em: 24 mai. 2005.

U.S. FOOD AND DRUG ADMINISTRATION. Center for Food Safety and Applied Nutrition. Bacterial Pathogens Growth and Inactivation. In: Fish and fisheries products hazards and controls guidance. 3.ed. jun. 2001. Disponível em: <http:/ / seafood.ucdavis.edu/haccp/compendium/chapt19.htm>. Acesso em: 10 mai. 2005.

WALKER, G.C.; HARMON, L.G. Thermal resistance of Staphylococcus aureus in milk, whey and phosphatase buffer. Applied Microbiology, v.14, n.4, p.584-590, 1966.

WILSON, I.G.; COOPER, J.E.; GILMOUR, A. Detection of enterotoxigenic Staphylococcus aureus in dried skimmed milk: use of the polymerase chain reaction for amplification and detection of staphylococcal enterotoxina genes ent $\mathrm{B}$ and ent $\mathrm{C} 1$ and the thermonuclease gene nunc. Applied and Environmental Microbiology, v.57, n.6, p.1793-1798, 1991.

WONG, A.C.L.; BERGDOLL, M.S. Staphylococcal food poisoning. In: CLIVER, DO; RIEMANN, H.P. Foodborne Diseases. 2.ed. Amsterdam: Academic Press, 2002. p.231248.

WORLD HEALTH ORGANIZATION. Emerging and other communicable diseases, surveillance and control: Report of a WHO consultation of public health implications of consumption of raw milk and meat and their products, Germany, 17-20, December, 1995.(WHO/EMC/ ZOO/96.7). Disponível em: <www.who.int/hq/1996/ WHO_emc_zoo96.7.pdf>. Acesso em: 3 set. 2005.

ZECCONI, A.; HAHN, G. Staphylococcus aureus in raw milk and human health risk. Bulletin of IDF, Brussels,v.345, p.15-18, 2001.

ZOLI, J.A.; NEGRETE, I.R.A.; OLIVEIRA, T.C.R.M. Avaliação da contaminação por Staphylococcus aureus e Salmonella spp. de maionese de batata comercializada em Londrina, PR. Higiene Alimentar, v.16, n.95, p.62-70, 2002.

Recebido em 31/3/09

Aceito em 13/4/10 